\title{
Insect Visitation to Wildflowers in the Endangered Garry Oak, Quercus garryana, Ecosystem of British Columbia
}

\author{
A. L. PARAChNOWitsCh and E. Elle
}

Department of Biological Sciences, Simon Fraser University, Burnaby, British Columbia V5A 1S6 Canada

Parachnowitsch, A. L., and E. Elle. 2005. Insect visitation to wildflowers in the endangered Garry Oak, Quercus garryana, Ecosystem of British Columbia. Canadian Field-Naturalist 119(2): 245-253.

The Garry Oak Ecosystem (GOE) is a fragmented and endangered ecosystem in Canada, and is currently the focus of conservation and restoration efforts in British Columbia. However, little is known about the basic biology of GOE forbs, or their relationships with pollinating insects. We monitored wildflowers and their insect visitors in 25 quadrats within a $25 \times 25$ metre plot, located in a fragment of the GOE near Duncan, British Columbia, for six weeks (the majority of the flowering period). Overall, 21 native and non-native forb species flowered in our quadrats during the survey, and we observed an additional six forb species flowering outside of our quadrats. Eight forbs were visited within quadrats by a total of 13 insect taxa, identified to morphospecies. Visits by eight additional morphospecies were observed outside of the quadrats. In general, visitation was low; however, most insect morphospecies were observed visiting more than one plant species, and most plant species were visited by more than one insect morphospecies, suggesting that pollination may be generalised in this community. A $\chi^{2}$ analysis indicated that insect visitation was not proportional to the relative abundance of forbs, with higher than expected visitation to Common camas (Camassia quamash), and no observed visits to 11 species, most with very small (putatively unattractive) flowers. The most frequent insect visitor was the introduced Honeybee, Apis mellifera, followed by native mason bees (Osmia spp.) and mining bees (Andrena spp.). Our observations provide baseline data for future, detailed studies that should investigate the importance of plant-pollinator mutualisms for sustainability of populations and communities in this rare ecosystem.

Key Words: Garry Oak Ecosystem, Quercus garryana plant-pollinator interactions, Common Camas, Camassia quamash, British Columbia.

The Garry Oak Ecosystem (GOE), an open woodland habitat dominated by Garry Oak (Quercus garryana), is increasingly of conservation concern. The GOE ranges from California to British Columbia (Erickson 2000), and within British Columbia is restricted to dry, nutrient-poor sites within the Coastal Douglas-fir biogeoclimatic zone (Klinka et al. 1996). Since western settlement, the GOE has become highly fragmented, with as little as $1 \%$ of its original area still remaining (Fuchs 2001). There are currently 117 GOE plant and animal species listed as endangered, threatened or vulnerable by the Committee on the Status of Endangered Wildlife in Canada (COSEWIC), and/or the British Columbia, Ministry of Sustainable Resource Management, and in Canada, the entire ecosystem is considered endangered (Garry Oak Recovery Team $2003 *)$.

Historically, the GOE has been maintained by fire disturbance and large-scale aboriginal cultivation (harvesting, weeding, replanting and controlled burning) of Camassia quamash (Common Camas) bulbs (Thilenius 1968; Turner and Kuhnlein 1983; MacDougall et al. 2004). However, European settlers imposed fire suppression and livestock grazing, leading to the encroachment of conifers into the GOE, and also introduced several highly invasive species; e.g., Cytisus scoparius (Scotch Broom) and Poa pratensis (Kentucky Blue Grass; Thilenius 1968; MacDougall et al. 2004). Fire suppression, non-native species introductions, and conversion of land to agricultural or urban use have fragmented the GOE, and current research aims to understand the implications of this fragmentation for Q. garryana establishment (Fuchs et al. 2000; Regan and Agee 2004) and to manage invasive and native species (e.g., Ussery and Krannitz 1998; Tveten and Fonda 1999; MacDougall and Turkington 2004). However, little is known about the basic ecology of native herbaceous forb communities within the GOE beyond status reports of a few rare species (Douglas and Illingworth 1997, 1998; Douglas and Ryan 1998; Penny and Douglas 2001) and studies of the reproductive biology of Aster curtus (currently Sericocarpus rigidus; Clampitt 1987; Bigger 1999; Giblin and Hamilton 1999).

One area of special concern is the paucity of data on plant-pollinator interactions within the GOE (Fuchs 2001). Pollination can be central to recruitment and maintenance of individual species, and can thereby provide an essential ecosystem service (Kearns et al. 1998; Black et al. 2001). Habitat loss and fragmentation, agricultural practices such as herbicide and pesticide use, and the encroachment of non-native species can all negatively impact plant and pollinator populations, and may disrupt the interaction between them as well. For example, two recent reviews highlighted that increased fragmentation leads to an increased probability of pollinator failure and reduced plant reproductive success (Aizen et al. 2002; Wilcock and Neiland 2002). These effects can be exacerbated by increased inbreeding depression in small populations (e.g., Severns 2003; Kephart 2004). Even highly local 
fragmentation can reduce pollinator visitation rates and seed production, and lead to greater expression of inbreeding depression within metapopulations (Lennartson 2002).

Most of the aforementioned studies relating habitat loss to pollination issues focus on single plant species. It is essential, however, to first determine the relationships between interacting communities of plants and pollinators, so as to direct future research towards those interactions likely to be most important either for single-species conservation or for community-level restoration. An improved understanding of the reproductive ecology of native GOE forbs could lead to more effective management tactics. Thus, we investigated visitation patterns of potential insect pollinators to a forb community in a remnant of the GOE. Our goal was to determine the richness and abundance of visiting insect taxa and patterns of insect visitation to GOE forbs, in order to provide baseline data on plantpollinator interactions within the GOE. Specifically we asked:

(1) What forbs are present and what insects visit them?

(2) How diverse are the insect visitors and do insect taxa visit only one plant species or many?

(3) How do forb abundance and insect visitation change throughout the season?

\section{Methods}

\section{Field Site}

The Cowichan Garry Oak Preserve near Duncan, British Columbia $\left(48^{\circ} 48^{\prime} 30.8^{\prime \prime} \mathrm{N}, 123^{\circ} 37^{\prime} 52.5^{\prime \prime} \mathrm{W}\right)$ is a 12.3 ha remnant of the GOE which once encompassed as much as 45000 ha throughout the Cowichan Valley. Within the private preserve (owned by the Nature Conservancy of Canada) there are a number of large, forb-dominated gaps in the woodland, one of which we chose for study. The Nature Conservancy of Canada actively manages the area, primarily through removal of $C$. scoparius.

\section{Forb surveys}

Prior to flowering in 2002, we laid out a $25 \times 25 \mathrm{~m}$ plot which encompassed the majority of the woodland gap. Within each $5 \times 5 \mathrm{~m}$ cell of the plot, a $0.5 \mathrm{~m}^{2}$ rectangular sampling quadrat was randomly located, for a total of 25 quadrats. The number of flowering stems was counted for each forb within each quadrat in six, weekly surveys from 23 April until 30 May. This period encompassed the majority of the flowering season (see Results). Voucher specimens of all forbs were deposited in the Simon Fraser University Herbarium, Burnaby, British Columbia. Plant identification follows Douglas et al. (1998). For each of the forbs present, we also present estimates of flower size and flower number per inflorescence based on Douglas et al. (1998; Table 1) as floral traits are known to affect insect visitation patterns.

\section{Floral visitor surveys}

Several different methods can be used to assess the community of floral visitors, each with positive and negative attributes. Because we were interested in the interaction between plants and potential pollinators for the entire plant community, and wanted to impact the site as little as possible, we used a combination of direct observation and pan trapping for this research. Direct observation of visitors to flowers allows the best description of relationships between plants and potential pollinators, and so was our method of choice. Direct observation of visitation, however, does not usually allow complete identification of floral visitors "on the wing". Survey methods like pan trapping or sweep netting can increase the total insect "catch" and allow for accurate identification of captured specimens, but information gained has limited utility for communitylevel studies as these methods do not allow evaluation of interactions between plants and visitors and frequently capture insects that are not floral visitors. In addition, sweep netting can damage plants by breaking off flowering stems. Because we wanted to increase our number of captured insects for identification, we used pan traps as the less damaging capture method. Floral visitor surveys were performed from 23 April to 23 May, and then were terminated as there were few flowering stems remaining.

\section{Direct observations}

Each of the 25 quadrats was observed for two, 15minute periods each week by two observers. Observations were made on sunny days between 09:00 and 17:00, and the order of quadrat observation was randomised for each of the two observers. A visit was counted if an insect was observed probing at least one flower on a plant. Insect taxa were identified based on morphological features visible in the field (morphospecies) and representative specimens of each morphospecies were collected between observation periods and identified as completely as possible in the lab. Because of low visitation rates and our desire to minimize our impact on pollinator populations, we collected only enough specimens to confirm morphospecies. In most cases morphospecies contain several taxonomic species, a limitation of the direct observation method, and so our identifications to genus will under-represent the taxonomic diversity of floral visitors. For example, Osmia sp. 1 are large-bodied Osmia (approximately $1 \mathrm{~cm}$ long) and include $O$. lignaria, $O$. texana, and possibly other species with similar appearance on the wing, but not captured for inclusion with our voucher specimens. Because visitation rates were generally low (see Results), visits to flowering stems outside the quadrats were also recorded. These casual observations may have been biased towards larger, more apparent insects, but are included in an effort to make visitation data as complete as possible. 

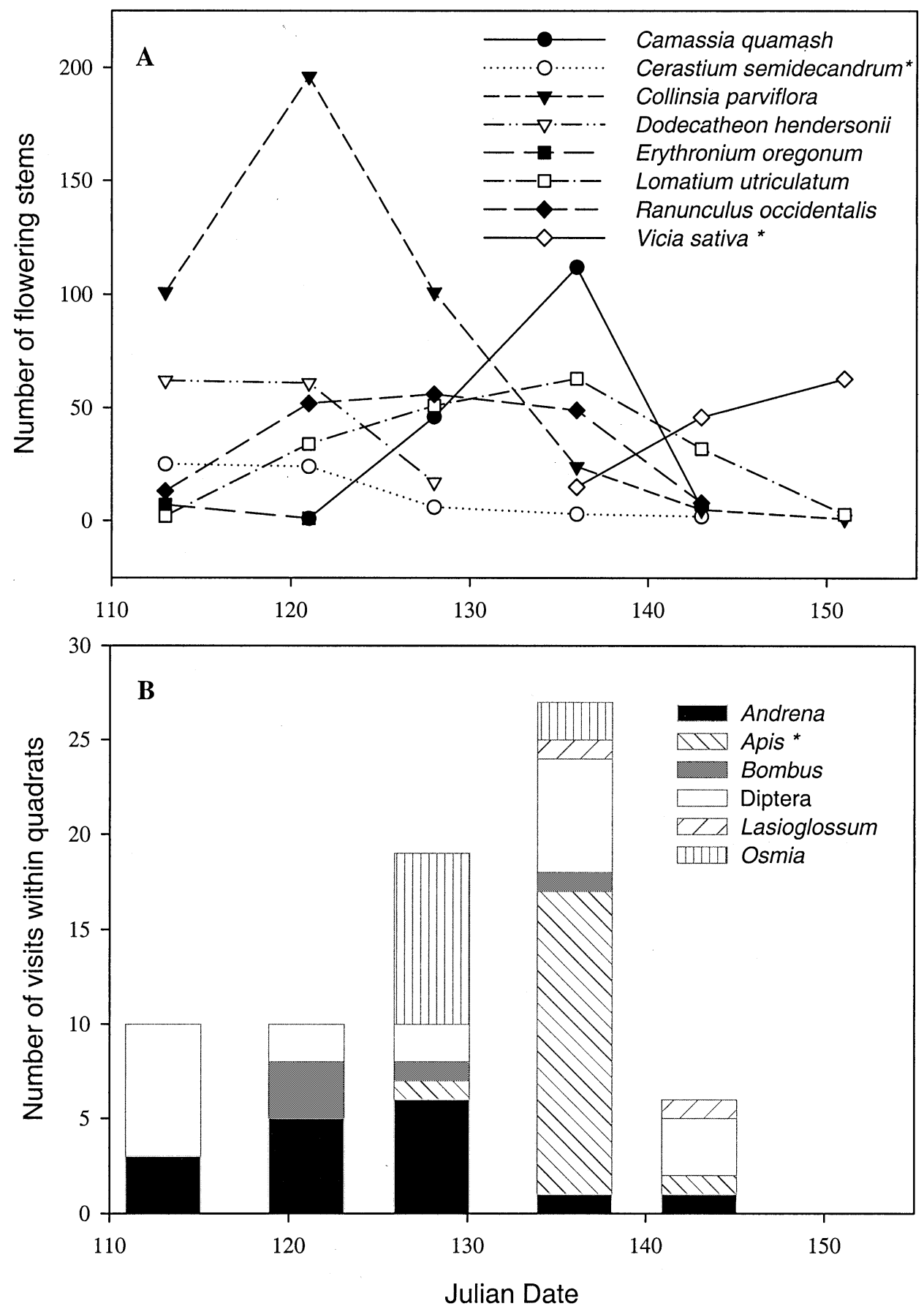

FIgURE 1: A. (top) Phenology and abundance of visited plant species (within quadrats) at the Cowichan Garry Oak Preserve. B. (bottom) Phenology of insect visitation within quadrats grouped by genus of visitors (family for Diptera). An asterisk (*) indicates non-native species origin. No observations of floral visitors were made during the last floral survey due to the large number of quadrats with few or no flowering stems. 
TABLE 1. List of flowering plant species sampled in quadrats, followed by six other species that we observed flowering at the Cowichan Garry Oak Preserve but which were not present in quadrats. An asterisk (*) indicates non-native origin, and a dagger $(\dagger)$ indicates an endangered or threatened species. Peak flowering date includes the total number of flowering stems in all quadrats. Small, medium and large flower size estimates indicate flower diameters $<1 \mathrm{~cm}, 1-3 \mathrm{~cm}$, and $>3 \mathrm{~cm}$, respectively. Flower number indicates plants that usually have few open flowers per stem $(<10)$ or many $(>10)$, unless indicated more precisely (Douglas et al. 1998).

\begin{tabular}{|c|c|c|c|c|}
\hline Scientific name & Common name & $\begin{array}{l}\text { Peak flowering } \\
\text { date (\# stems) }\end{array}$ & $\begin{array}{l}\text { Flower } \\
\text { size }\end{array}$ & $\begin{array}{l}\text { Flower } \\
\text { number }\end{array}$ \\
\hline Cardamine sp. & Bitter-cress & 23/04/02 (12) & small & few \\
\hline Camassia quamash & Common Camas & $16 / 05 / 02(112)$ & large & $5+$ \\
\hline Cerastium arvense & Field Chickweed & $31 / 05 / 02(6)$ & medium & few \\
\hline Cerastium semidecandrum ${ }^{*}$ & Little Mouse-ear & 23/04/02 (25) & small & few \\
\hline Claytonia perfoliata & Miner's-lettuce & 01/05/02 (13) & small & few \\
\hline Collinsia parviflora & Blue-eyed Mary & 01/05/02 (196) & small & $1-$ many \\
\hline Cytisus scoparius* & Scotch Broom & 23/05/02 (3) & medium & many \\
\hline Dodecatheon hendersonii & Broad-leaved Shootingstar & $23 / 04 / 02(62)$ & medium & $2-15$ \\
\hline Erythronium oregonum & White Fawn Lily & 23/04/02 (7) & large & usually 1 \\
\hline Galium aparine & Cleavers & $16 / 05 / 02(600)$ & small & many \\
\hline Geranium molle* & Dovefoot Geranium & 23/05/02 (15) & medium & $2-$ many \\
\hline Lathyrus sphaericus* & Grass Peavine & 23/05/02 (37) & medium & few \\
\hline Lithophragma parviflorum & Small-flowered Woodland Star & $01 / 05 / 02(1)$ & medium & $5-11$ \\
\hline Lomatium utriculatum & Spring Gold & $16 / 05 / 02(63)$ & small & many \\
\hline Montia linearis & Narrow-leaved Montia & $23 / 04 / 02(4)$ & small & many \\
\hline Myosotis discolor* & Common Forget-me-not & $31 / 05 / 02(4)$ & small & many \\
\hline Phlox gracilis & Slender Phlox & $16 / 05 / 02(14)$ & small & many \\
\hline Ranunculus occidentalis & Western Buttercup & 08/05/02 (56) & medium & few \\
\hline Sanicula crassicaulis & Pacific Sanicle & $23 / 05 / 02(3)$ & small & many \\
\hline Valerianella locusta* & Corn Salad & $16 / 05 / 02(758)$ & small & many \\
\hline Vicia sativa* & Common Vetch & $31 / 05 / 02(63)$ & medium & few \\
\hline \multicolumn{5}{|l|}{ Also flowering at the site: } \\
\hline Achillea millefolium & Yarrow & & small & many \\
\hline Fritillaria affinis & Chocolate Lily & & large & $1-5$ \\
\hline Sericocarpus rigidus $\dagger$ & White-top Aster & & small & many \\
\hline Triteleia grandiflora var. howellii† & Howell’s Brodiaea & & medium & many \\
\hline Viola praemorsa ssp. praemorsa $\dagger$ & Yellow Montane Violet & & medium & few \\
\hline Zygadenus venenosus & Meadow Death-camas & & medium & many \\
\hline
\end{tabular}

\section{Pan trapping}

A set of three pan traps (yellow, white, and blue to reduce colour bias: Leong and Thorp 1999) was placed at a random point along each of the five north-south transects making up the $25 \times 25 \mathrm{~m}^{2}$ grid (i.e., five sets). Pans were filled with ca. $250 \mathrm{~mL}$ of water and a few drops of glycerol (Kearns and Inouye 1993) and set out on each observation date for at least 6 hours. Captured insects were preserved in ethanol prior to identification. Identification of Hymenoptera, Lepidoptera and Diptera followed Michener et al. (1994), Guppy and Shepard (2001) and McAlpine et al. (1981), respectively. Voucher specimens of all morphospecies were deposited with the Simon Fraser University Natural History Museum.

\section{Statistical analyses}

To illustrate the overall patterns of visitation, we present a matrix of the interactions between forbs and putative pollinator morphospecies (Table 1) and calculate the sum of interaction types for both the forb species and insect morphospecies. For each sampling date, we used a $\chi^{2}$ analysis to test whether the number of visits to each plant species (summed across quadrats) was proportional to the number of available stems of each species. All plant species that were flowering within quadrats on a particular date were included in these analyses. To test whether visitation patterns were determined by the phenology of the forbs (i.e., that later-flowering species had more visits), we performed a regression of the total number of visits a plant species received (pooled over all dates and quadrats) on peak species flowering date (1) including all species, and (2) including only the eight forbs that received visits, to avoid bias due to the many zero values for unvisited species.

\section{Results}

Twenty-one forb species were observed flowering within quadrats, 14 native and 7 non-native (Table 1). Most of the species had small (11 species) or medium (8 species) flower size while only Camassia quamash and Erythronium oregonum had large flowers (greater than $3 \mathrm{~cm}$ diameter); 10 of the species generally pro- 


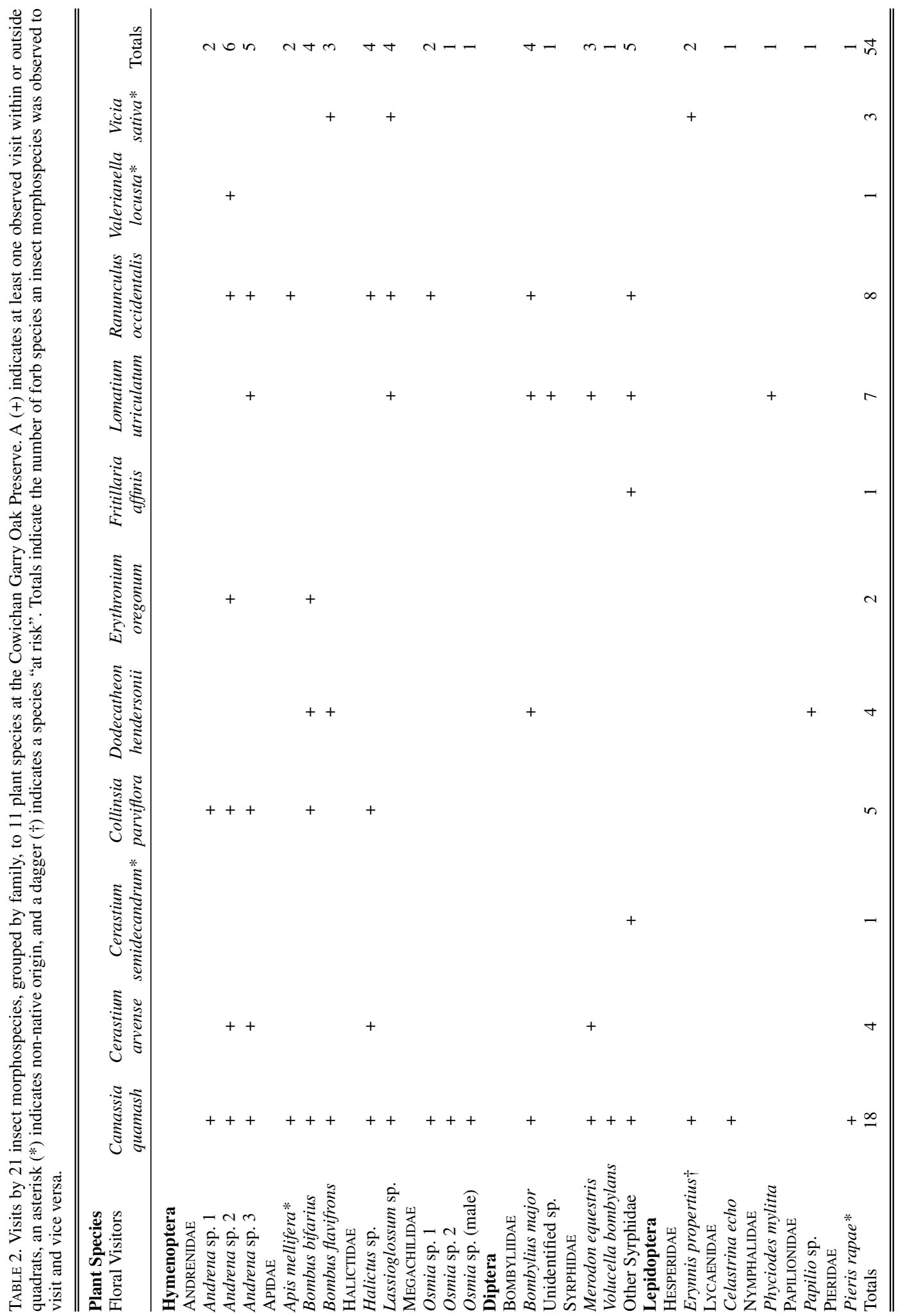


duce fewer than 10 flowers per flowering stem (Table 1). Only 10 of the forb species had a density greater than 2 flowering stems $/ \mathrm{m}^{2}$ in our quadrats on their peak flowering date (Table 1). Our sampling period captured the peak spring flowering period of 13 of these species (Table 1, Figure 1A); five species had a peak flowering date before the start of the survey (or on 23 April), including Cardamine sp., Cerastium semidecandrum, Dodecatheon hendersonii, Erythronium oregonum and Montia linearis while only Cerastium arvense, Myosotis discolor, and Vicia sativa continued to increase in abundance after the survey. Six additional native forb species were present at the site, including three species at risk, but were not present in our sampling quadrats due to low frequency or patchy distribution (Table 1).

Visitation frequency was low (0.5-3.9 visits/hr). Flower visitors were observed on 11 forb species (Table 2) but on only 8 of the 21 forbs available within the quadrats (Table 3 ). On four of the five sampling dates the number of visits to each forb species was different from that expected based on the number of flowering stems available ( 23 April $: \chi^{2}=28.7, \mathrm{df}=8$, $P=0.0004$; 1 May: $\chi^{2}=12.8, \mathrm{df}=13, P=0.4666 ; 8$ May: $\chi^{2}=101.7, \mathrm{df}=11, P<0.0001 ; 16$ May: $\chi^{2}=312.7$, $\mathrm{df}=15, P<0.0001 ; 23$ May: $\chi^{2}=182.1, \mathrm{df}=16, P<$ $0.0001)$.

Thirteen insect morphospecies were observed visiting forbs flowering within quadrats, and eight additional morphospecies were observed visiting forbs at the site (Table 4). Hymenoptera accounted for the largest percentage of visits within quadrats (71.4\%) with the remaining visits by Diptera. Osmia sp. 1 were large-bodied mason bees, Osmia sp. 2 were small-bodied mason bees; Andrena morphospecies were distinguished based on relative size, abdominal markings, and dense hairs on the thorax. "Other Syrphidae" refers to the common, striped hoverflies such as species of Syrphus and Metasyrphus which could not be distinguished on the wing. The majority of observed visits were made by Apis mellifera (honeybee), followed by the native Osmia and Andrena spp. (Table 4). Within quadrats, A. mellifera was observed visiting C. quamash exclusively, and $88.9 \%$ of observed A. mellifera visits occurred during the date of peak $C$. quamash bloom. Most floral visitors did not exhibit this fidelity, however; 13 of the 21 morphospecies observed visited more than one forb species, and eight of the 11 visited forb species were visited by more than one insect morphospecies (Table 2). As the season progressed, more visits from a greater number of insect morphospecies were observed until most of the forbs had senesced (Figure 1B). Although there were more visits observed later in the season, there was no relationship between peak flowering date and the number of visits received by a plant species $\left(\mathrm{R}^{2}=0.0002, F_{1,19}=0.00, P=0.96\right)$, even when only the eight visited forbs were considered $\left(\mathrm{R}^{2}=0.079, F_{1,7}=0.52, P=0.50\right)$.
TABLE 3. Number of floral visits observed within quadrats by insect morphospecies. Visits are summed across quadrats, the eight visited plant species and surveys from 23 April to 23 May 2002.

\begin{tabular}{llr}
\hline \hline Floral visitors & \# Visits & $\begin{array}{c}\% \text { of } \\
\text { Visits }\end{array}$ \\
\hline Hymenoptera & & \\
Andrena sp. 1 & 1 & 1.4 \\
Andrena sp. 2 & 9 & 12.9 \\
Andrena sp. 3 & 4 & 5.7 \\
Apis mellifera & 18 & 25.7 \\
Bombus bifarius & 4 & 5.7 \\
Bombus flavifrons & 1 & 1.4 \\
Lassioglossum sp. & 2 & 2.9 \\
Osmia sp. 1 & 10 & 14.3 \\
Osmia sp. (male) & 1 & 1.4 \\
Diptera & & \\
Bombylius major & 6 & 8.6 \\
Unidentified bombyliid sp. & 3 & 4.3 \\
Volucella bombylans & 2 & 2.9 \\
Other Syrphidae & 9 & 12.9 \\
\hline \hline
\end{tabular}

TABLE 4. Distribution of observed visits (all insect species combined) among the 8 plant species that received visits within quadrats. Data derived by pooling across all quadrats and observation periods (23 April to 23 May, 2002). An asterisk (*) indicates non-native origin.

\begin{tabular}{lrc}
\hline \hline Plant species & \# Visits & $\begin{array}{l}\% \text { of } \\
\text { Visits }\end{array}$ \\
\hline Camassia quamash & 37 & 52.9 \\
Cerastium semidecandrum* $^{*}$ & 1 & 1.4 \\
Collinsia parviflora & 8 & 11.4 \\
Dodecatheon hendersonii & 5 & 7.1 \\
Erythronium oregonum & 1 & 1.4 \\
Lomatium utriculatum $_{\text {Ranunculus occidentalis }}$ & 7 & 10.0 \\
Vicia sativa* $^{*}$ & 10 & 14.3 \\
\hline \hline
\end{tabular}

Pan traps caught only nine individuals throughout the sampling period, including four Andrena (species 2, 3 and one additional morphospecies not seen during the observation periods), one Osmia male (a different morphospecies than the male Osmia seen during the observation period), one Volucella bombylans, two of the unidentified Bombyliid observed visiting flowers, and a male Megachile sp. that was not observed visiting flowers. Low catches precluded further analysis.

\section{Discussion}

Visitation rates within this fragment of the GOE were low in 2002 (maximum rate 3.9 visits/hr of observation, on 16 May), but eight of 11 forb species that received visits were visited by more than one insect morphospecies and 13 of the 21 insect morphospecies were observed visiting more than one plant species (Table 2). Because of the low number of visitors observed, it is difficult to make inferences about the 
degree of specialisation of individual insect morphospecies; however, most visited forbs appear to have generalised insect visitation patterns. Similarly generalised visitation patterns were observed at the same site in 2001, although visitation rates were higher (Elle and Carney 2003). In that survey, conducted over a shorter time (equivalent to our third and fourth census dates) and so not inclusive of the flowering period of many GOE forbs, visitation by 14 insect morphospecies to just four forb species (all visited by multiple morphospecies) was observed at a rate of 28.5 visits/hr. Among-year variation in visitation rate is not uncommon in spring-flowering communities (e.g., Motten 1986; Burd 1994), but it is unknown whether the unpredictability of visitation limits reproductive success of GOE forbs.

The number of observed visits to each forb species differed from that expected based on flowering stem availability on all but one sampling date, suggesting some degree of preference on the part of insect visitors. Camassia quamash was visited by the most diverse group of insects (16 of the 21 observed morphospecies) and received the majority of visits $(52.9 \%)$. On its peak flowering date (16 May), C. quamash was common (flowering in 22 of 25 quadrats), and received 24 of the 26 observed visits. This forb produces large flowers on multi-flowered inflorescences (Table 1), and may have high nectar rewards. In contrast, the majority of forbs within our quadrats with no observed visits (9 of 11) have small and/or few flowers (Table 1), and may be less attractive to insect foragers; several are likely self-fertilised (i.e., Galium aparine, Montia linearis, Myosotis discolor). Although low visitation rates temper our conclusion of non-random visitation, similarly non-random visitation was observed at this site the year before the current study (Elle and Carney 2003).

The composition of the flowering forb community and the insects that visited them changed over the duration of our study (Figure 1). It is possible that the phenological differences in forb abundance influenced visitation. For instance, $C$. quamash was the most abundant plant on 16 May, which coincided with the greatest number of observed visits, in particular by Apis mellifera, which visited $C$. quamash almost exclusively (Figure 1B). However, the results of the regressions of number of insect visits on peak flowering date suggest that flowering later does not lead to increased total visitation; we suggest instead that $C$. quamash is simply highly attractive to insects.

The high abundance and diversity of visitors to $C$. quamash (at least relative to other plants) suggests that it may have an important ecological role in this community; it may serve as a "magnet" species for pollinators and enhance pollination of neighbouring species by increasing the overall size and/or diversity of the pollinator community (Thomson 1978; Laverty 1992). The only pollinator species that were present but not observed visiting $C$. quamash included rarely observed species (two Lepidoptera; Table 2) and pos- sibly a specialist fly (the unidentified Bombyliid was observed numerous times outside the quadrats but only visiting Lomatium utriculatum). Our study did not address interactions of $C$. quamash with other plants in the community; however, the relatively high frequency and variety of visitors to $C$. quamash suggests that future research could test whether this species has competitive or facilitative effects on forb pollination within the GOE.

Bees were the most common floral visitors in our study and are major pollinators globally (Kearns and Inouye 1997). Early in the sampling period, Osmia and Andrena spp. were frequently observed (Figure 1B), although the most frequently observed visitor overall was Apis mellifera (honeybee), which has been introduced world wide from Europe and is used for crop pollination (Kearns and Inouye 1997). Apis mellifera has been implicated in the decline of native pollinators (Kearns et al. 1998 and references therein; Goulson 2003; Thomson 2004) and so its potential impacts on plant-pollinator relationships in the GOE need to be considered. Our study did not address interactions between A. mellifera and other bees. However, A. mellifera visited $C$. quamash almost exclusively both in the present study and a previous study at this site (Elle and Carney 2003), and thus the potential for negative effects on other pollinators will depend on the importance of $C$. quamash as a nectar or pollen resource for native pollinators (which generally visited other plants in addition to $C$. quamash, Table 2). Our data do suggest that if native pollinators were to decline for reasons other than competition with honeybees (e.g., loss of appropriate nesting habitat), A. mellifera would not provide pollination services for plant species other than C. quamash.

Our study provides initial data on plant-pollinator interactions in the GOE, but additional, detailed study is necessary to determine the importance of plantpollinator mutualisms for the sustainability of the community as a whole. Further research is needed to determine the effectiveness and importance of insect visitors for pollination of GOE forbs, and whether these insects are at risk due to habitat or nesting requirements. The numerous forb species for which we've never observed any visits, at both the Cowichan Garry Oak Preserve and other sites (Elle and Carney 2003) should be investigated to determine if they are, indeed, reproducing maximally via autogamy, or if they are instead pollen limited. Our data suggest that pollination of visited plant species may be generalized, however, and so this ecosystem may be resilient to the loss of individual pollinating insect species (Waser et al. 1996). More research is important to determine whether rare GOE forbs are at risk due to failed mutualisms (e.g., Bond 1994).

\section{Acknowledgments}

The authors thank T. Ennis and the Nature Conservancy of Canada for access to the Cowichan Garry Oak Preserve. J. Biernaskie, S. Campbell, C. Caruso, B. 
Husband, M. Schuetz and two anonymous reviewers provided constructive feedback on earlier versions of the manuscript, and J. Biernaskie, M. Schuetz, and M. Thane provided field assistance. Funding was provided through an Undergraduate Student Research Award to A.L.P. and an operating grant to E.E., both from the Natural Sciences and Engineering Research Council of Canada.

Documents Cited (marked $*$ in text)

Garry Oak Ecosystem Recovery Team. 2003. http://www. goert.ca. Accessed online May 2004.

\section{Literature Cited}

Aizen, M. A., L. Ashworth, and L. Galetto. 2002. Reproductive success in fragmented habitats: do compatibility systems and pollination specialization matter? Journal of Vegetation Science 13: 885-892.

Bigger, D. S. 1999. Consequences of patch size and isolation for a rare plant: pollen limitation and seed predation. Natural Areas Journal 19: 239-244.

Black, S. H., M. Shepard, and M. M. Allen. 2001. Endangered Invertebrates: the case for greater attention to invertebrate conservation. Endangered Species Update 18: 4149.

Bond, W. J. 1994. Do mutualisms matter? Assessing the impact of pollinator and disperser disruption on plant extinction. Philosophical Transactions of the Royal Society of London 344: 83-90.

Burd, M. 1994. Bateman's principle and plant reproduction: the role of pollen limitation in fruit and seed set. The Botanical Review 60: 83-111.

Clampitt, C. A. 1987. Reproductive biology of Aster curtus (Asteraceae), a Pacific Northwest endemic. American Journal of Botany 74: 941-946.

Douglas, G. W., and J. M. Illingworth. 1997. Status of the White-top Aster, Aster curtus (Asteraceae) in Canada. The Canadian Field-Naturalist 111: 622-627.

Douglas, G. W., and J. M. Illingworth. 1998. Status of the Water-plantain Buttercup, Ranunculus alismifolius var. alismifolius (Ranunculaceae) in Canada. Canadian Field-Naturalist 112: 280-283.

Douglas, G. W., and M. Ryan. 1998. Status of the Yellow Montane Violet, Viola praemorsa ssp. praemorsa (Violaceae) in Canada. Canadian Field-Naturalist 112: 491495.

Douglas, G. W., G. B. Straley, D. Meidinger, and J. Pojar. 1998. Illustrated Flora of British Columbia. B.C. Ministry of Environment, Lands, and Parks, Victoria, British Columbia, Volumes 1-5.

Elle, E., and R. Carney. 2003. Reproductive assurance varies with flower size in Collinsia parviflora (Scrophulariaceae). American Journal of Botany 90: 888-896.

Erickson, W. 2000. Garry oak communities in Canada: classification, characterization and conservation. International Oaks 10: 40-54.

Fuchs, M. A., P. G. Krannitz, and A. S. Harestad. 2000. Factors affecting emergence and first-year survival of seedlings of Garry Oaks (Quercus garryana) in British Columbia, Canada. Forest Ecology and Management 137: 209219.

Fuchs, M. A. 2001. Towards a recovery strategy for Garry Oaks and associated ecosystems in Canada: Ecological assessment and literature review. Technical report GBEI/
EC-00-030. Environment Canada, Canadian Wildlife Service, Pacific and Yukon region.

Giblin, D. E., and C. W. Hamilton. 1999. The relationship of reproductive biology to the rarity of endemic Aster curtus (Asteraceae). Canadian Journal of Botany 77: 140-149.

Goulson, D. 2003. Effects of introduced bees on native ecosystems. Annual Review of Ecology, Evolution and Systematics 34: 1-26.

Guppy, C. S., and J. H. Shepard. 2001. Butterflies of British Columbia. UBC Press, Vancouver, Canada.

Kearns, C. A., and D. W. Inouye. 1993. Techniques for Pollination Biologists. University Press of Colorado, Niwot, Colorado.

Kearns, C. A., and D. W. Inouye. 1997. Pollinators, flowering plants and conservation biology. BioScience 47: 297307.

Kearns, C. A., D. W. Inouye, and N. M. Waser. 1998. Endangered mutualisms: the conservation of plant-pollinator interactions. Annual Review of Ecology and Systematics 29: 83-112.

Kephart, S. R. 2004. Inbreeding and reintroduction: Progeny success in rare Silene populations of varied density. Conservation Genetics 5: 49-61.

Klinka, K., H. Qian, J. Pojar, and D. V. Meidinger. 1996. Classification of natural forest communities of coastal British Columbia, Canada. Vegetatio 125: 149-168.

Laverty, T. M. 1992. Plant interaction for pollinator visits: a test of the magnet species effect. Oecologia 89: 502-508.

Lennartsson, T. 2002. Extinction thresholds and disrupted plant-pollinator interactions in fragmented plant populations. Ecology 83: 3060-3072.

Leong, J. M., and R. W. Thorp. 1999. Colour-coded sampling: the pan trap colour preferences of oligolectic and nonoligolectic bees associated with a vernal pool plant. Ecological Entomology 24: 329-335.

MacDougall, A. S., B. R. Beckwith, and C. Y. Maslovat. 2004. Defining conservation strategies with historical perspectives: a case study from a degraded oak grassland ecosystem. Conservation Biology 18: 455-465.

MacDougall, A. S., and R. Turkington. 2004. Relative importance of suppression-based and tolerance-based competition in an invaded oak savanna. Journal of Ecology 92: 422-434.

McAlpine, J. F., B. V. Peterson, G. E. Shewell, H. J. Teskey, J. R. Vockeroth, and D. M. Wood. 1981. Manual of Nearctic Diptera. Research Branch, Agriculture Canada, Ottawa, Ontario.

Michener, C. D., R. J. McGinley, and B. N. Danforth. 1994. The bee genera of North and Central America (Hymenoptera: Apoidea). Smithsonian Institution Press, Washington, D.C.

Motten, A. F. 1986. Pollination ecology of the spring wildflower community in a temperate deciduous forest. Ecological Monographs 56: 21-42.

Penny J. L., and G. W. Douglas. 2001. Status of the Purple Sanicle, Sanicula bipinnatifida (Apiaceae), in Canada. Canadian Field-Naturalist 115: 460-465.

Regan, A. C., and J. K. Agee. 2004. Oak community and seedling response to fire at Fort Lewis, Washington. Northwest Science 78: 1-11.

Severns, P. 2003. Inbreeding and small population size reduce seed set in a threatened and fragmented plant species, Lupinus sulphureus ssp. kincaidii (Fabaceae). Biological Conservation 110: 221-229.

Thilenius, J. F. 1968. The Quercus garryana forests of the Willamette Valley, Oregon. Ecology 49: 1124-1133. 
Thomson, D. 2004. Competitive interactions between the invasive European honey bee and native bumble bees. Ecology 85 : 458-470.

Thomson, J. D. 1978. Effects of stand composition on insect visitation in two-species mixtures of Hieracium. American Midland Naturalist 100: 431-440.

Turner, N. J., and H. V. Kuhnlein. 1983. Camas (Camassia spp.) and riceroot (Fritillaria spp.): two Liliaceous "root" foods of the Northwest Coast Indians. Ecology of Food and Nutrition 13: 199-219.

Tveten, R. K., and R. W. Fonda. 1999. Fire effects on prairies and oak woodlands on Fort Lewis, Washington. Northwest Science 73: 145-158.
Ussery, J. G., and P. G. Krannitz. 1998. Control of Scot's Broom (Cytisus scoparius (L.) Link.): the relative conservation merits of pulling versus cutting. Northwest Science 72: 268-273.

Waser, N. M., L. Chittka, M. V. Price, N. M. Williams, and J. Ollerton. 1996. Generalization in pollination systems, and why it matters. Ecology 77: 1043-1060.

Wilcock, C., and R. Neiland. 2002. Pollination failure in plants: Why it happens and when it matters. Trends in Plant Science 7: 270-277.

Received 18 October 2002

Accepted 5 April 2005 